\title{
Open System Design Strategies Towards a More Inclusive Architecture
}

\author{
ALMUDENA RIBOT \\ Penn State University
}

In this paper we will examine the different strategies that allow architecture to adapt to change and reprogramming. We will discuss buildings that are able to morph through time and use and work towards a definition of what could be considered an Open System in our postdigital era. These kinds of architectures are inclusive in two ways: they accept both changing needs and multiple agents, during the design process and over the life time of the building itself.

Flexibility and adaptability aroverused words but they remain key issues for all architects. Today there is significant increase in interest in both from the point of view of construction and use. This research works to find ways to introduce the capacity for change and interaction into architectural design, to accommodate uncertainty, the unknown and the demands of passing time.

To do this we need to identify the principal methods used to achieve flexibility in main stream, popular and vanguard architectural culture and more specifically in individual buildings where these strategies have been applied.

This paper works to construct a dialogue between the ideas in Adrian Forty's Words and Buildings: a vocabulary of Modern Architecture (T \& H, 2004) and Tatjana Schneider and Jeremy Till's Flexible Housing, (Architectural Press, 2007). We will develop a diagram to help us combine these two sets of ideas and then extend that diagram to a more practical and sustainable application of them. The diagram constitutes a non hierarchical categorisation in which issues and case studies have the same weight, it is both a taxonomy and an atlas of methods and case studies. The process is both deductive and inductive, considering general principles and case studies.

\section{OPEN SYSTEM DESIGN STRATEGIES}

The question of Flexibility is an on going preoccupation in architectural history. Today our rapidly changing lifestyles and technologies make it more important than ever before. Three main factors determine this fact:

As citizens we live in a Rolling society in which our mobility is essential, we change houses, work, family structure, financial and social status. In this precarious post digital age everything is in flux. As citizens we need flexibility of use: spaces that can adapt as our lives change.
As architects we need more constructive flexibility. The new ways in which buildings are being made and used oblige us to rethink our relationship to the user. The new hybrid term formed from the words consumer and producer: Prosumer ${ }^{1}$ identifies very well how the boundaries between consumption and production have blurred, how we participate more actively in the management and production of what we consume. Architecture is as prone to this change as any other practice. Users often expect to be co-producers of their own spaces, living or otherwise, and we must reorganize the design and the construction world to allow their participation without loosing architectural vigour or intensity.

As human beings we now need flexibility that is also sustainable. Environmental concerns, in what has now been defined as our Anthropocene age, make us reconsider the waste of continuous construction. We must address the concerning fact that construction is responsible for the $40 \%$ of $\mathrm{CO} 2$ global emissions. We can not continue to build without addressing this problem.

Our age demands this triple flexibility; in use, construction and sustainability. This work will explore ways to balance and combine these three aspirations.

\section{HISTORY}

Wars bring about advances in construction. After war the reconversion of armament industries to peace time needs combined with the necessity for urban renewal drive pre-war innovative architectural ideas forward.

After the First World War, during the 1920s, there were significant advances in more open and inclusive systems of architecture. They evolved on several fronts: In 1927 in Weissenhofsiedlung, (Stuttgart) Mies van der Rohe was the first architect to address the need for flexibility of use. He foresaw different configurations for the interiors of his proposal, separating the constructive systems where partitions walls are isolated from the structural frame so that it was possible to modify distribution according to necessity. At the same time industrialization and engineering in construction was advancing a pace. Walter Gropius' proposal for the same exhibition is a case in point but there were many other architects working in this field using different systems: Fuller's Dymaxion House was designed in the same year. There were also advances in strategies for temporal adaptability; in 1931 Gropius worked with Hirsch Kupfer to create innovative Increased Houses that could expand over time and combined standardization with variability. ${ }^{2}$ 
After World War II industrialized building systems progressed significantly. There was a drive to create new standards in compatibility, universal solutions, and mass construction that required flexibility as a tool. The Packaged House is a ground breaking example of a prefabricated modular construction system, a major collaborative effort between Walter Gropius and Konrad Wachsmann that lasted a decade from 1941 until the end of The General Panel Factory in $1950 .{ }^{3}$ It is not surprising that one of the first statements in favour of flexibility comes again from Walter Gropius: "1. That the architect should conceive buildings not as monuments but as receptacles for the flow of life which they have to serve, and 2. that his conception should be flexible enough to create a background fit to absorb the dynamic features of our modern life."

However, it was in the 1960s when the most important advances in flexibility occurred and the relationships between architects, citizens and users were radically transformed. After the trauma of post war reconstruction people began to participate in large scale public projects: collective collaborations united public and private institutions. There was active participation of citizens in political issues and policy making and women entered the work place in significant numbers. Unprecedented consumer choice in America and the welfare state in much of Europe. These things all happened in parallel, or because of, significant new technologies: cybernetics, effective contraception, plastics, new fabrics. These radical changes in the structure of society changed peoples behaviour from largely passive to active participant citizens. Architects were not immune to these shifts of role. There was a move away from the idea of the author architect: creator, artist, western white male and other ways of working become possible: new groups of architects emerge characterised by social concerns and interest in new technologies. These architects understood the new needs and embraced users who expected more participation. In the vanguard of 60 s architecture there are key figures who opened up the discipline to collaboration. The architect John Habraken stands out as one of the first and his work has had a profound influence, but he is not alone; almost simultaneously similar proposals arose from Nieuwenhuys Constant, Yona Friedman, the Japanese Metabolists, Cedric Price and some others. In 1961 we find Bakema \& Van den Broek designing Growing Houses. These use very different models from those of Walter Gropius' Increased Houses they allow users the freedom to decide when and how they are going to increase their houses and are not bound to a constructive system.

During 1970s and 1980s the search for adaptability looses momentum in mainstream architectural culture. There are some exceptions: Herman Hertberger, Simone \& Lucien Kroll, Ralph Erskine, Anarchitecture Group, Ant Farm and others continue to look for solutions. Though the consumers of architecture continued to look for more collaboration in design very little attention is paid to them until nearly 25 years later.

\section{EXERCISE}

According to Adrian Forty flexibility in architecture is achieved in three ways which he defines as: Redundancy, Technical Means and Political Strategies in his book Words and Buildings: a Vocabulary of Modern Architecture. He understands Redundancy in the engineering sense of the term: the inclusion of extra space which is not necessary to the functioning of the building, the inclusion of both margins and spaces with no predetermined use. He quotes Koolhaas' statement: "Flexibility is not the exhaustive anticipation of all possible changes. ... flexibility is the creation of margin- excess capacity that enables different and even opposite interpretations." ${ }^{\prime 5}$ When discussing Technical Means, he focusses clearly on mobile systems. He defines his third model, Political Strategy, as the appropriation of space by occupants, suggesting that this could become an architecture issue: leaving space for future use: air as architecture. We support with this analysis, architecture is a political issue and can influence social behaviour, "air as architecture" is a vital area for research.

Tatjana Schneider y Jeremy Till contribute further to this debate in their book Flexible Housing. ${ }^{6}$ Approaching the question from a mainly social perspective they distinguish between two important issues: flexibility of use and constructive flexibility. As architects we know that these are different questions that do not go hand in hand. In their analysis which concentrates on flexibility for the user they grade examples from soft to hard. Soft architecture includes those buildings which accept change of use and can be easily appropriated by the user. Hard architecture is predetermined space with function planned at the design stage. These two kinds of architecture are dramatised as opposing forces, and the authors are crusaders defending users need for soft flexibility from "hard" architects. According to Scheneiders/Tills' understanding architects see users as operators of complex equipment and love to design complicated mobile systems that predeterminate building use. We will appropriate their terminology and use the Hard and Soft analogy on a graph axis which architects and users can play with.

In this exercise we unite Forty and Schneider/Tills' analysis of flexibility by placing the three kinds of flexibility that Forty has defined along the gradient Soft/Hard proposed by Scheneider and Till. On the $x$-axis we place the degree of constructive difficulty from soft to hard. On $\mathrm{Y}$ - axis we place the degree of flexibly for the user again from soft to hard. We also further develop the three categories and refine the definitions by creating subgroups informed by our practical experience as architects.

Once we conceived this graphic exploration of flexibility we saw there was a need to include processes that predate definitions of flexibility. We identified three previous areas where really significant steps have been taken towards flexibility and inclusivity. We have named this category Protoflexibility and its subgroups: Election, Nomadism and Participation. 
We have three goals in developing this diagram:

1. To express these compound ideas around inclusive/ flexible architecture visually so they can be more clearly understood, signposting clear and urgent pathways for research towards Open Systems.

2. To identify practical strategies for achieving architectural adaptability to change, reprogramming and appropriation.

3. To find a balancing point where our three key issues: Flexibility for the user; Construction; Sustainability.

\section{DIAGRAM}

[Protoflexibility/ Election] Choosing a distribution from a larger offer, even if the choice is limited, it means that need and preference are taken into account. This is not the conventional commercial offer of different sizes and numbers of bedrooms, we are interested in proposals that contain different ways of living in the same design. Habitat 67 by Moshe Sadfie and Silodam by $M R D V$ are good examples of this. Both use the same strategy of offering dwelling variability but respond in two different ways according to the historical and environmental context. Habitat 67 (1967) uses materially identical modules of different sizes to propose diversity for an enclosed group of people of similar social profile. The housing project Silodam (1995-2003) proposes one compact block for everybody but aiming for diversity of shape, size, color, living conditions and view. Different ways of living for diverse people. Two examples that demonstrate how election can be used as a procedure towards Open Systems
[Protoflexibility/Nomadism] Moving the situation of a living space: the place we live can give the user a feeling of freedom and flexibility. Nomadism is of course an ancient life style. Giedion explains how American colonial houses could be moved from one place to another, he sites the Phillip House ${ }^{7}$ which is the result of joining two houses moved from different places and then extended with a third addition between the two; all possible because of their timber construction. The famous Spartan Mobile Home from the 1950s is a perfect example of the American tradition of mobility as is the picturesque practice of Tiradura de Casas on the Chiloé island in Chile. Again, thanks to the lightness and structural articulation of its timber construction these houses can be "dragged" from island to island according to necessity. These kinds of traditional nomadic practices should not be ignored in research for different kinds of flexibility in future practice.

[Redundancy /Margins] If we define Redundancy as inclusion of excess margins to allow for appropriation or change of use over time we think of Lofts or Ateliers. These spaces were not designed to be residential but came to be used as homes by artists and Bohemians during the 1960s and 70s. This kind of flexibility, made up of cubic meters, is easy to design but difficult to maintain and democratize: more space per person is more expensive and more volume means higher energy consumption. However, there are modern examples that use redundancy in a more rational way. Combining the buildings services and infrastructure as at the Curtain Wall House by Sigheru Ban. Concentrating the determined parts of the building and leaving free the undetermined space as

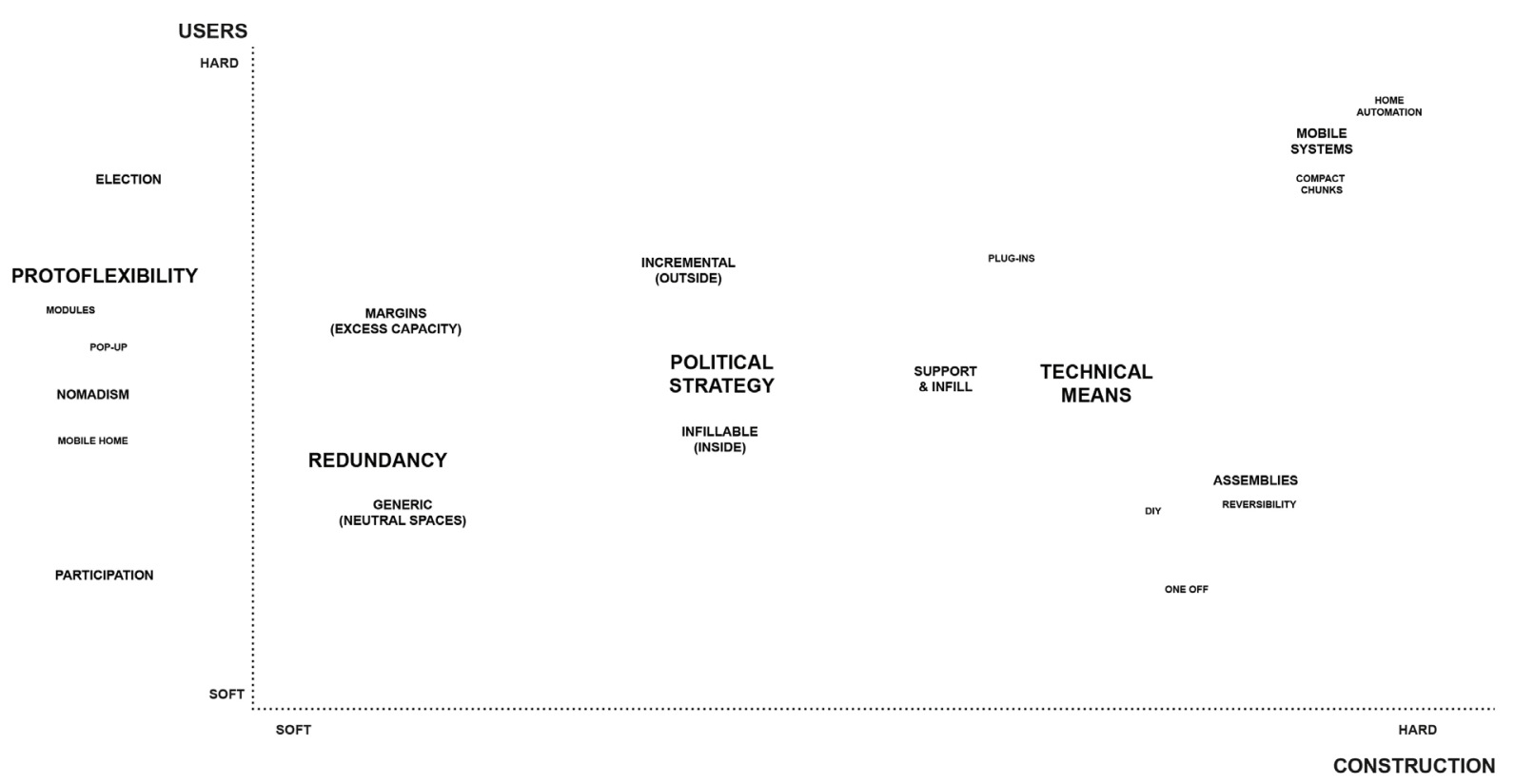

Figure 1. Open System diagram extended their specific gradients [Adrian Forty three Flexibility categories following Schneider and Till gradients] (author's edition). 


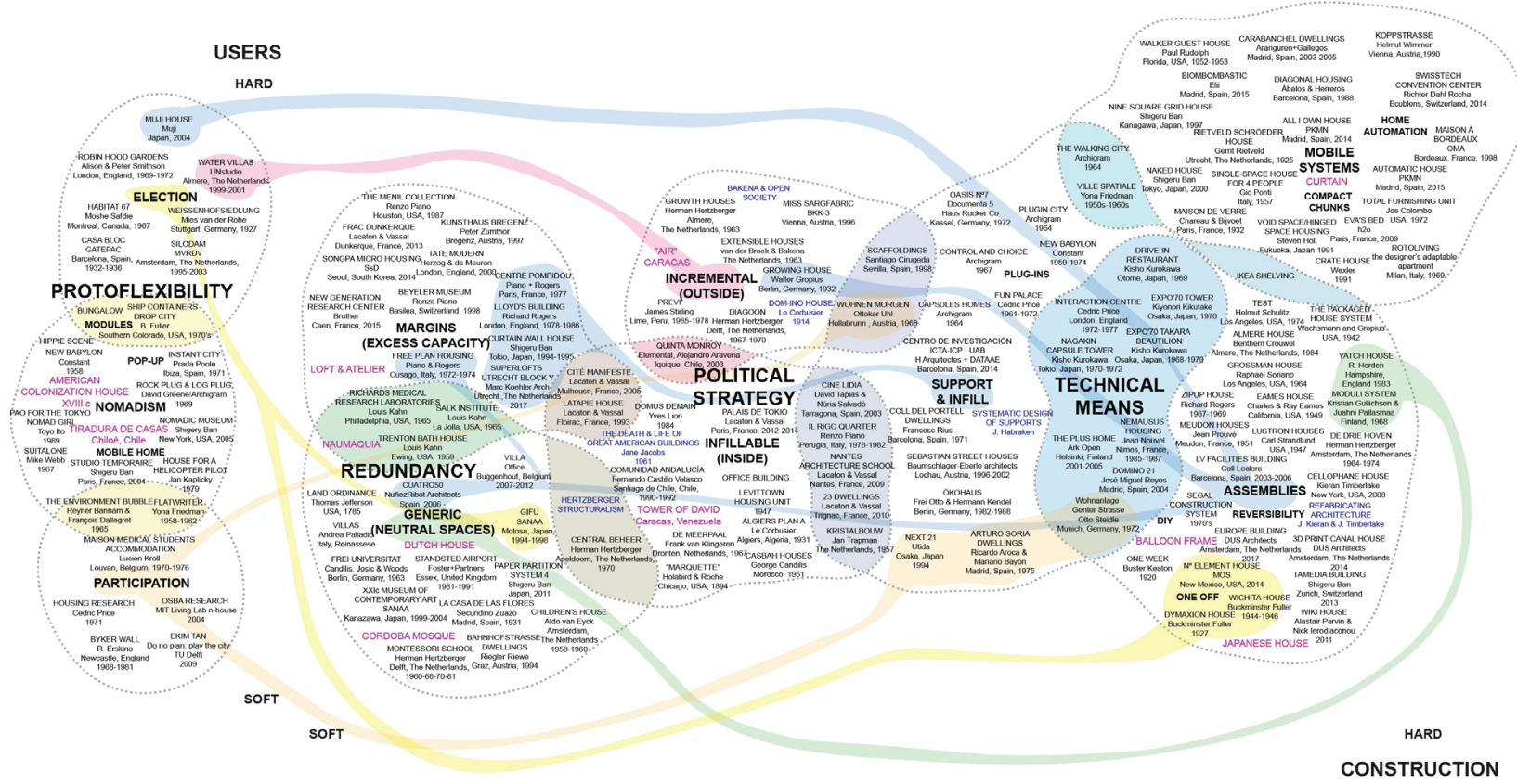

Figure 2. Open System Design Strategies Diagram with hybrid cases and extremes relationships.

Lacaton \& Vassal do in their Dunkerque Center or leaving a margin of space without qualification, as in Mulhouse Houses and the Plus projects. There is a wide field for research into incorporating redundancy for long term flexibility.

[Redundancy /Generic] We define this as the repetition of similar spaces without hierarchies and no corridors to speak of, rooms whose function is defined by activity and furniture, and cite The Canal Houses of Holland, as a paradigm; always the same and always different. The 16 century villas of Palladio contain similar and neutral interconnected spaces where even the stairs are not given hierarchical importance. A radical example is the Land Ordinance Proposal by Thomas Jefferson in 1785 (US president and architect). This is a grid division proposed for every scale, from territory to bedroom. Kazuyo Sejima demonstrates how to work with non hierarchal independent elements in her Stadstheater in Almere (1998), this strategy for flexibility is proving popular again in contemporary architecture.

[Political Strategy/Incremental] In Spanish cities one can see billboards high up that read "Vendo aire" (Air for Sale). They are offering cubic meters of air for sale over the existing building, for future extensions. Buildings can increase upwards as far as the structure with allow or until it is impossible to build or to live so high. Notable for its size and ambition is the experimental residential complex in Lima; Previ (1969). In this competition James Stirling's Growing Houses were very interesting, he proposed the incremental part of the house around a tradition courtyard which would be used for future vertical connections. The work of the dutch structuralists, in particular the Diagoon Houses by Hertzberger as an example of incremental housing is currently receiving attention again, although perhaps the most widely documented case are the houses of Quinta Monroy (2003) designed by Alejandro Aravena. This is a very interesting solution where only the middle of the house is built, what he calls the Elemental part, leaving all lateral space available for future development. Clearly incremental design: the incorporation of space conceived for future appropriation, is a Political Strategy, in the hands of architects in these cases.

[Political Strategy / Infill] To design a container for infill is both an Open System and an inclusive strategy with much potential. Users can appropriate free space over time and also they do not have problems, as often occurs, with expanding the building's perimeter space as it is clearly defined. The system also provides the advantage of a homogenous exterior image. In the classic American office building, a much more advanced typology than housing, we find pioneering archetypal examples. The buildings of the Chicago School, in particular Marquette by Holabird \&Roche from 1894, in which the lifts are concentrated in the centre of the building and the interiors were left completely empty. A relatively unknown but very interesting case of this method is the Comunidad Andalucia (1992) by architect Fernando Castillo Velasco in Santiago de Chile. This very economic proposal completed all the exteriors while leaving the interiors (up to three levels) completely empty. Users were left to complete their own dwellings according to need and budget. This is a procedure that demands attention in today's world with its vast inequalities of wealth. 


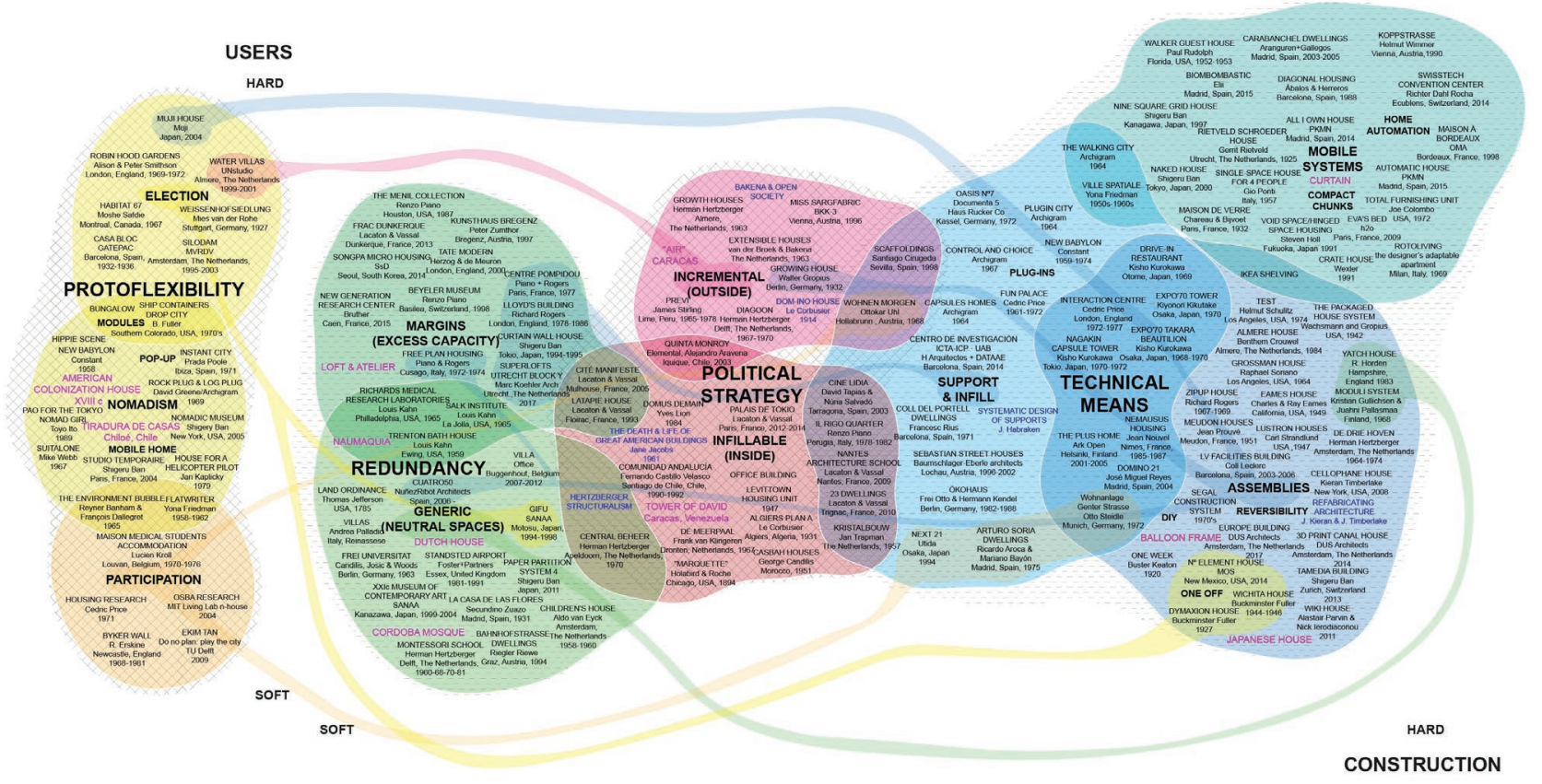

Figure 3. Open System Design Strategies Diagram.

[Technical Means / Assemblies] Industrialization of building processes is essential in moving towards an Open System that allows a more inclusive architecture. In fact, in one way or other, industrially prefabricated construction systems have been used in almost all the later historical examples quoted in this paper. Working with compatible elements that are easily put together with dry construction allows us to think of the action of assemblage as editing and is the process that defines the final building. Two archetypal models explain in themselves the advantages of assembly: the traditional Japanese House and the Balloon Frame timber construction. The first is the most sophisticated version of assemblage and the second is the simplest one. A great part of their success and longevity is that both are anonymous and tap into collective knowledge. In the contemporary Cellophane House Kieran \& Timberlake rely entirely on industrially produced prefabricated building components with reversibility and zero energy waste as goals. The relative ease and participative possibilities of Assembly as a building process has obvious advantages.

[Technical Means: Support \& Infill] Physically separating parts of a building is a very useful strategy that allows us to change, remove or add elements independently. We can separate communal area from private ones and so separate responsibilities. We can isolate the permanent infrastructural spaces from contingent ones and so we can replace only the necessary ones, achieving a longer life for the whole as it easily accommodates change. Leading the field with this practice are The Open Building movement, heir to the theories of John Habraken as expressed in his book Supports: An Alternative to Mass Housing (1961).
Attractive and visually self explanatory cases are the Project Ökohaus (literally Eco-House) by Frei Otto and others (built as a participative experiment the IBA 86 Architectural Berlin Exhibition) and Next 21 by Utida and others in Osaka, Japan. In both cases each individual house in the complex has a different model and design. The Nakagin Tower by Kurokawa also follows this pattern with a visually striking Plug-in exercise that separates the infrastructure from the infill. This methodology needs to be developed, support and infill can become much more efficient than in the past, with more compatibility between subsystems and user participation opened up by the internet.

[Technical Means: Mobile Systems] Mobile systems have always allowed spatial flexibility. Room dividing curtains are a simple archetypal example of a device that has been successfully dividing spaces for flexibility, intimacy, organiziation and energy control up until very recently. The Schröder House by Rietveld (1924) is a model of interior mobility with its sophisticated system of sliding and revolving panels. Rem Koolhaas' chooses to modify the space vertically in his House in Bordeaux with a moving platform elevator. While historically mobile systems have often only existed in the architectural imagination, more theoretical than practical, thanks to new technology this is now changing. The developing technology and parametrization allow us to design moving and interactive components within complex mobile systems that are at the same time simpler and more accessible. With the press of a button we can completely transform a domestic space or an auditorium so it is not hard to understand why mobile Systems are currently experiencing a renaissance. 


\section{CONCLUSION}

The diagram shows us that the two understandings of flexibility that Forty and Schneider- Till offer us can be developed and combined in a meaningful way, and by adding more specific breakdowns every case finds its place. This taxonomy works but it is not the only possible one, as is usual categorization does not answer all questions, but the act of organization itself helps us understand how things work and relate to each other. We can observe relationships between extremes of the diagram that help us to imagine other models, with others tags and others results. Architects must continuous look for tools that permit these adaptive methods: systematization, industrialization, customization, digital fabrication and new materials.

As demonstrated by the last subgroup of Technical means: Mobile Systems, procedures that have been considered Hard could become Soft in the near future. This is why the diagram itself must be flexible and open. It is just the first step in our research, a specific cross section of this area of architecture. In the near future we would like to develop a three-dimensional atlas taking in users, construction and sustainability with an Open System evaluation of multiple cases incorporating the parameters we have found here. The one thing we know for sure is that everything changes and by exploring these procedures for adaptability we can help bring about the architectural transformation we urgently need: From Mass- production to Mass- customization, from composition to assemblage, from fixed to flexible, from closed to open, from wasteful to sustainable, from exclusive to inclusive.

\section{ENDNOTES}

1 "Prosumer" was coined in 1980 as it is explained in D. Tapscott and A.D. Williams, Wikinomics: How Mass Collaboration Changes Everything (London: Atlantic Books, 2007), 328: "Alvin Toffler first coined the term "prosumer" in his book The Third Wave (New York: Bantam Books, 1980)."

2 Walter Gropius used the Hirsch Kupfer System. Berlin Exhibition 1932.

3 The General Panel company was set up in Burbank, California in 1946 (1945 WWII finished)

4 Forty quotes Gropius in 1954: Adrian Forty, "Flexibility" in Words and Buildings: A Vocabulary of Modern Architecture (London: Thames \& Hudson 2000), 142.

5 Forty, 144. Koolhaas's quote refers to prison, which is practical but not flexible. "In relation to the Koepel at Arnhem a circular Panopticon-type ninetheenthcentury prison building" as Forty himself says.

6 Tatjana Schenider and Jeremy Till, Flexible Housing (UK: Taylor \& Francis Ltd.,2007).

7 S. Giedion, Espacio tiempo y arquitectura, fifth edition, ed., Dossat (1978), 377 Original version: S. Giedion, Space, Time \& Architecture: The Growth of a New Tradition (Cambridge, MA: Harvard University Press, 1941). 